\title{
Ant guards influence the mating system of their plant hosts by altering pollinator behaviour
}

\author{
Nora Villamil,, $3^{*}$ Karina Boege, ${ }^{2}$ and Graham N. Stone ${ }^{1}$ \\ 'Institute of Evolutionary Biology, University of Edinburgh, Ashworth \\ Laboratories, The King's Buildings, Edinburgh, EH9 3FL, United Kingdom. \\ ${ }^{2}$ Instituto de Ecología, Universidad Nacional Autónoma de México. \\ A.P. 70-275. Ciudad Universitaria, C.P. 04510, Ciudad De México. México. \\ 3 Current address: Department of Ecology and Evolution, Université de \\ Lausanne, Biophore, $\mathrm{CH}-1015$, Lausanne, Switzerland. \\ *Correspondence: noravibu@gmail.com \\ Running title: Ecological and evolutionary costs of ant patrolling \\ Key Words: male fitness, mating systems, myrmecophily, non-pollinators, \\ outcrossing, plants. \\ Statement of authorship: NV conceived the ideas and designed the \\ experiments. NV conducted fieldwork, processed, and analysed the data. NV \\ led the writing of this paper, with critical inputs from KB and GS. \\ Word count: Abstract (145), Main text (4746) \\ Number of: References (48), Figure (5), Tables (1), Text boxes (o) \\ *Corresponding author: Nora Villamil, Institute of Evolutionary Biology, \\ University of Edinburgh, Ashworth Laboratories, The King's Buildings, \\ Edinburgh, EH9 3FL, United Kingdom. Email: noravibu@gmail.com.
}


31 Abstract

32 Ant guards can increase plant fitness by deterring herbivores but may also

33 reduce it by interfering with pollination, hence ant-plant interactions are ideal

34 systems in which to study costs and benefits of mutualisms. While ant impacts

35 on herbivory are well-studied, much less is known about impacts on

36 pollinators and associated consequences for plant mating systems and fitness.

37 We used field experiments to quantify the effect of ant guards on pollinator

38 community composition, frequency and duration of flower visits, and

39 cascading effects on plant mating system and plant fitness in Turnera velutina

40 (Passifloraceae). Although ant patrolling did not affect pollinator community

41 composition or visitation frequency, it decreased pollinator foraging time and

42 flower visit duration. Such behavioural changes resulted in reduced pollen

43 deposition on stigmas, decreasing male fitness whilst increasing outcrossing

44 rates. This study contributes to understanding how non-pollinators, such as

45 these defensive mutualists, can shape plant mating systems. 


\section{Introduction}

49 Ant-plants are excellent systems in which to explore the costs and benefits of

50 multispecies mutualisms. While aggressive ants increase plant fitness by

51 defending their host plants from herbivores (Bentley 1977; Beattie 1985; Martin

52 \& Doyle 2003), they can also decrease plant fitness disrupting plant-pollinator

53 mutualisms and repelling other plant-beneficial predatory arthropods (Koptur

54 et al. 2015). Ants can disrupt pollination by consuming floral structures,

55 damaging pollen (Stanton et al. 1999; Frederickson 2009; Stanton \& Palmer

56 2011; Dutton \& Frederickson 2012; Malé et al. 2015), or deterring flower

57 visitation by pollinators (Assunção et al. 2014; Villamil et al. 2018).Yet,

58 information on their impacts on pollinators, pollen transfer and seed set is still

59 limited, and only few studies have addressed the ecological costs of ants via

60 pollinator deterrence (Romero \& Koricheva 2011).

Ant aggressivity may be a double-edged sword underlying the core ecological costs and benefits of myrmecophily. More aggressive ants may be better defenders against herbivores, but may also pose a higher predation risk

64 to other mutualistic guilds such non-ant predators of herbivores or pollinators

65 (Ness 2006; Ohm \& Miller 2014; Jones \& Koptur 2015; Villamil et al. 2018).

66 Furthermore, the metrics commonly used in quantifying the effectiveness of

67 indirect defences against herbivores - reduction in damage by herbivores - are

68 unlikely to reveal pollination-associated impacts on plant fitness (Dukas 2001; 
69 Gaume et al. 2005; Ness 2006; Goncalves-Souza et al. 2008; Frederickson 2009;

70 Romero \& Koricheva 2011; Stanton \& Palmer 2011; Dutton \& Frederickson 2012;

71 Ohm \& Miller 2014; Jones \& Koptur 2015; Malé et al. 2015) and a multispecies

72 approach is needed to improve our estimates of the net outcomes of

73 mutualistic interactions.

Ant impacts on pollinators may be consumptive (through predation) or

non-consumptive, defined as changes in prey traits or behaviours in response

to perceived predation risk (Preisser et al. 2005; Sheriff \& Thaler 2014). The

magnitude of non-consumptive effects on pollinator and plant fitness can be

similar to, or higher than, that of direct consumptive effects (Preisser et al.

79 2005; Romero et al. 2011; Clinchy et al. 2013; Sheriff \& Thaler 2014). However,

80 the mechanism(s) by which predators influence pollinator behaviour and

81 impact on plant fitness remain entirely unknown for the majority of ant-plants

82 (Romero \& Koricheva 2011).

The few studies on the effects of ant patrolling on pollinator behaviour

suggest that ants can have positive or negative consequences for plant fitness.

85 For example, lower seed set in Ferocactus wislizenii plants tended by aggressive ants was attributed to a three-fold reduction in pollinator visitation

87 frequency (Ness 2006). However, this hypothesis was not experimentally tested. Alternatively, an increase in fruit set in ant-patrolled plants of

89 Psycothria limonensis was attributed to pollinator relocation, where ant

90 threats might have caused pollinators to spend less time per flower and visit 
91 more flowers, promoting pollen transfer (Altshuler 1999). Again, this

92 mechanism was inferred, but not experimentally tested. Previous experiments

93 on Turnera velutina showed that ant corpses placed inside flowers reduce

94 pollinator visit duration (Villamil et al. 2018). However, such an experimental

95 setup may differ from natural circumstances as flower occupation by ants is a

rare event, and live ants (in contrast to dead ones) do not remain immobile in

97 the flowers for long periods. Overall, the presence of ants can promote

changes in pollinator community composition, visit frequency and duration.

This, in turn, could drive positive or negative impacts of ant-pollinator

100 interactions on plant reproduction (Altshuler 1999; Ness 2006). To date, no

study has quantified the impacts of ant patrolling on pollinator visitation

behaviour, plant mating systems, and fitness under natural conditions.

We estimated the ecological and potential evolutionary consequences

of myrmecophily on the pollination biology, mating system, and fitness of

Turnera velutina (Passifloraceae), a self-compatible ant-plant using an ant

exclusion field experiment. We addressed the following questions: (i) What is

the effect of ant patrolling on pollinator visitation? (pollinator community

composition, visitation frequency, duration, and behaviour) (ii) Does ant

patrolling affect the host plant mating system? (iii) Does ant patrolling affect

110 pollen transfer dynamics? (iv) Does ant patrolling affect plant male fitness?

111 First, because smaller or solitary pollinator taxa are expected to be more

112 vulnerable to predation risk than larger or social species (Dukas \& Morse 2003)

113 (Clark \& Dukas 1994; Abbott \& Dukas 2009) we predicted that the pollinator 
114 community composition on ant-excluded plants should be biased, relative to

115 plants with ants, towards smaller and solitary taxa. Second, due to ant-

116 associated predation risk, we hypothesised that flowers of ant-occupied plants

117 would receive fewer and shorter pollinator visits, with higher rates of flower

118 avoidance (pollinator failure to land). Last, we had three different predictions

119 for the effects of ants on pollinator visitation and plant mating system,

120 depending on the magnitude of ant-related impacts on pollinator behaviour:

121 (a) Ants strongly deter pollinators, leading to reduced visitation frequency,

122 shorter visits, pollinator limitation, and reduced seed set in ant-occupied

123 plants. (b) Ants partially deter pollinators forcing them to relocate to other

124 flowers within the same plant, leading to higher visitation frequency but

125 reduced visit duration and higher rates of geitonogamy (intra-plant

126 pollination) in ant-occupied plants. (c) Ants partially deter pollinators, forcing

127 them to relocate to flowers of different plants, leading to higher visitation

128 frequency but reduced visit duration, and higher outcrossing rates (inter-plant

129 pollination) in ant-occupied plants, increasing seed genetic diversity.

\section{Materials and methods}

132 Study site and system

133 Field experiments were conducted in coastal sand scrub at Troncones,

134 Guerrero, on the southern Pacific coastline of Mexico $\left(17^{\circ} 47^{\prime} \mathrm{N}, 101^{\circ} 44^{\prime} \mathrm{W}\right.$,

135 elevation $<50 \mathrm{~m}$ ). Turnera velutina (Passifloraceae) is a Mexican endemic 
136 shrub (Cuautle \& Rico-Gray 2003; Arbo 2005) that establishes a facultative

137 mutuaalism with 10 ants species in Troncones (Zedillo-Avelleyra 2017)

138 rewarding them with extrafloral nectar (Villamil et al. 2013). Turnera velutina is

139 a self-compatible, herkogamous species that requires pollinators for seed

140 production (Sosenski et al. 2016). Although it flowers year-round, flowering

141 peaks during summer (Cuautle et al. 2005) and the entomophilous flowers last

142 one day (Sosenski et al. 2016). Pollinator rewards are pollen and floral nectar

143 (Sosenski et al. 2016; Villamil et al. 2018). At Troncones, native butterflies are

144 the dominant flower visitors of T. velutina, followed by the introduced

145 honeybee (Apis mellifera); native bees, wasps, and occasionally flies also visit

146 the flowers.

148 Ant exclusion and experimental setup

149 We identified six replicate arrays of plants, each of which was at least $10 \mathrm{~m}$

150 from any other array, and comprised two large focal plants producing $>6$

151 flowers per day, and separated by $>\mathbf{2} \mathrm{m}$. One focal plant was randomly

152 designated as control, with natural levels of ant-guards. The second was

153 designated ant-excluded, excluding ants from all stems using Tanglefoot ${ }^{\mathrm{TM}}$

154 (Fig 1a). Both focal plants in each array were isolated from other plants by

155 trimming or tying back any surrounding vegetation. Exclusion treatments

156 were checked daily and Tanglefoot ${ }^{\mathrm{TM}}$ was replenished if required. Each focal

157 plant pair was surrounded by 6-10 neighbouring adult plants of T. velutina $>2$

158 m away (Fig. 1a). 
To assess the effect of ant patrolling on pollen transfer and its consequences on the rate of selfing, geitonogamy, and outcrossing, we dyed

161 the anthers and pollen of control and ant-excluded plants, using four contrasting dyes (red, blue, green or purple) (Fig. 1b). Within each focal plant, one flower was designated as a focal flower, whilst the other five flowers were designated satellite flowers (Fig. 1a). The anthers of the focal flower were dyed using one colour, whilst the anthers of all satellite flowers were dyed in a second colour. The remaining two colours were used on the other focal plant within the array, differentially dyeing the anthers of focal and satellite flowers (Fig. 1a). Pollen from the neighbouring non-focal T. velutina plants within the array was left undyed (naturally yellow-orange). The dyeing treatment was

170 repeated in each of the six plant arrays.

172 satellite buds) were bagged to exclude visitors. All additional pre-anthesis buds

173 were removed to standardise floral display across focal plants. Once the corollas were fully open, anthers were dyed and flowers were re-bagged until

175 the dye dried and anthers dehisced, exposing the dyed pollen (Fig. 1b). To ensure a minimum common supply of allogamous pollen across all flower

177 pairs, 10-12 flowers from the neighbouring plants within the array were also

178 bagged before anthesis and remained bagged until the visitation observations started. Stigmas from focal flowers were collected at the end of the anthesis period to count pollen grains received, as detailed below (Fig. 1c). 


\section{Pollen dyes}

182 Anthers of focal and satellite flowers were dyed once the corolla opened

183 completely ( o80o-o815), but before anther dehiscence. Anthers were

184 individually embedded in a droplet of dye until soaked, and flowers were

185 bagged again until anthers dehisced and the released pollen was dry. The dyes

186 used were methyl violet (purple), Green S (green), safranin (red), and

187 methylene blue (blue) (for further details see Supplementary material).

188 Previous studies showed that dyeing Turnera velutina anthers in these colours

189 effectively dyed pollen grains had no effect on pollinator visitation (Ochoa

190 Sánchez 2016). Towards the end of anthesis (11:30), pistils from focal flowers

191 were collected in Eppendorf tubes and slide mounted as a glycerine squash

192 (Kearns \& Inouye 1993; Ochoa Sánchez 2016).

\section{Pollinator visitation}

We recorded pollinator visitation to all six flowers on control and antexcluded focal plants. Every focal plant was observed for two 20-minute periods - one immediately after bag removal when flowers had a full pollen and nectar load and the second 90 minutes later. Flowers remained bagged until their first observation round started to ensure all flowers had a full pollen and nectar load. We recorded the identity, frequency, duration, and behaviour of floral visitors and visits, as detailed below. We conducted a total of $40 \mathrm{~h}$ of observations of 360 flowers on 12 plants over five days. Statistical analyses were conducted in $\mathrm{R}$ version 3.5 ( $\mathrm{R}$ Core Team 2016). All mixed effects models were 
203 fitted using 'lme4' R package (Bates et al. 2016) and post-hoc Tukey

204

205 217 included in all further analyses.

a) Pollinator community composition

Flower visitors regarded as potential pollinators (hereafter pollinators) were identified to one of five taxonomic categories: Apis mellifera, native bees, butterflies, flies, and wasps. To estimate the overall abundance of pollinators from each taxonomic group, we pooled together observations from control and ant-excluded plants and calculated the percentage of visitors from each group. Within each of these taxonomic groups, differences in the total number of visitors between control and ant excluded plants were assessed using a Pearson Chi-squared test. Because Apis mellifera and butterflies jointly accounted for $94 \%$ of all visitors (Table S1), only these taxonomic groups were

b) Pollinator visitation frequency and duration

Flower visits were scored each time a pollinator hovered over, landed and contacted the reproductive organs of a flower, and visit duration was recorded until the pollinator departed. We recorded visitor identity and considered revisitation events. Visitor abundance was estimated as the number of individual visitors per taxa landing on flowers of a particular plant. For instance, a visitor 
224 that landed, hovered, and landed again in another flower was registered as two

225 visits from one visitor. Ant patrolling effects on visitation frequency were

226 tested using a Poisson mixed model. The effect of ant patrolling on visit

227 duration was tested using a Poisson mixed model.

c) Pollinator behavior

229 All pollinator visits were allocated to one of two behavioural categories

230 following Villamil et al. (2018): inspection (defined as a pollinator approaching

231 a flower without landing) or contact (landing on the flower). The effect of ant

232 patrolling on the likelihood of pollinators displaying inspection behaviours

233 was tested with a binomial mixed model, considering the presence or absence

234 of inspection behaviours as the response variable. The effect of ant patrolling

235 on pollinator deterrence was tested using a binomial mixed model. Pollinator

236 deterrence is here defined as the absence of contact behaviours following an

237 inspection behaviour. For every pollinator that displayed an inspection

238 behaviour, we recorded the presence or absence of contact behaviours and

239 fitted this as a binomial response variable. For instance, if a pollinator hovered

240 over a flower, without landing inside it, we would record a zero as the

241 response variable. The effect of ant patrolling on the duration of each type of

242 behaviour was tested using a Poisson mixed model, splitting observations into

243 inspection or contact behaviours. The total duration of each behaviour

244 (inspection or contact) per visitor was fitted as the response variable. 
247 The effect of ant patrolling on pollen transfer and its consequences on plant mating system was assessed by counting differentially dyed pollen grains on

249 focal flower stigma squash slides under a light microscope. The effect of ant 250 patrolling on stigma pollen load, defined as the total number of pollen grains received per stigma, was tested using a Poisson mixed model (Table 1). the same flower (selfing), another flower within the same plant (geitonogamy),

254 the other focal plant in the same array (outcrossing), or another un-dyed plant

255 (outcrossing). The number of pollen grains from each origin (selfing,

256 geitonogamy or outcrossing) was divided by the total number of pollen grains

257 stigma (pollen load) to determine the proportion of pollen from each mating

258 system source. Proportional data were transformed to normality using the

259 logit transformation, with infinite numbers resulting from impossible

260 quotients replaced by zeros. The effect of ant patrolling on the mating system

261 was tested using a linear mixed model, fitting the proportion of pollen from

262 each mating system as the response variable (Table 1).

Pollen transfer dynamics were analysed using five categories to describe the mating system and the pollen origin (hereafter referred to as MSPO; Fig. every possible pollen source identifiable in this experiment as follows: (i)

267 received/donated to the same flower (selfing), (ii) received from another 
268 flower from the same plant (geitonogamy received), (iii) received from the

269 reciprocal focal plant (outcrossing pair received), (iv) donated to the reciprocal

270 focal plant (outcrossing pair donated), (v) or received from another plant from

271 the same species (outcrossing unknown received). The effect of ant patrolling

272 on pollen flow dynamics was tested using a Poisson mixed model (Table 1),

273 fitting as the response variable the number of pollen grains in each of the five

274 MSPO categories.

275 Male plant fitness

276 The number of pollen grains donated per flower was an estimate for male

277 plant fitness and quantified as number of pollen grains from each flower

278 donated to focal stigmas. The total number of pollen grains from satellite

279 flowers on the same plant was divided by five, to obtain the mean number of

280 pollen grains donated per flower. The total number of pollen grains from the

281 other focal plant in the same array was divided by six ( 1 focal +5 satellite

282 flowers). The effect of ants on male fitness was estimated using a Poisson

283 mixed model fitting as the response variable the number of pollen grains

284 donated per flower in control or ant-excluded plants.

The effect of ant patrolling on the destination of the pollen grains

286 donated per flower was tested using a Poisson mixed model, fitting number of

287 pollen grains as the response variable. We only contrasted the number of

288 pollen grains donated by focal or satellite flowers, as every plant had exactly

289 six flowers because floral display was controlled for in our experimental 
290 design. Pollen donated by unknown plants was excluded as the number of

291 donor flowers was unknown, and hence pollen grains donated per flower

292 cannot be estimated.

294 Results (720 words)

295 Pollinator visitation: composition, frequency and duration

296 We recorded 967 floral visitors, of which 853 belonged to taxa we regarded as

297 potential pollen vectors (hereafter pollinators) because they were observed

298 contacting male and female plant sexual organs (Table 1), although

299 experimental analyses of their efficiencies as pollen vectors are required.

300 Butterflies and honeybees accounted for more than $80 \%$ of all floral visitors

301 and $>94 \%$ of potential pollinators (Table S1). Ant exclusion did not

302 significantly influence the community composition of pollinators visiting $T$.

303 velutina flowers $\left(X^{2}=1.42, \mathrm{df}=4, P=0.84\right.$; Fig. 2).

Visitation frequency did not differ significantly between pollinator

305 types, or between control and ant-excluded plants (Fig 3a, Table 1). The effect

306 of ant exclusion on visit duration varied across pollinator taxa, as indicated by

307 the significant interaction term (Fig. 4b, Table 1). While flower visits by

308 honeybees were twice as long in ant-excluded plants $(Z=2.45, P=0.05$; Table

309 1; Fig. 4b), there was no significant effect of ant patrolling on butterflies $(Z=$

$310 \quad$ 1.07, $P$ = o.70; Table 1; Fig. 4b). 
Pollinator behaviour

313 Inspection behaviours differed significantly between pollinator taxa (Table 1,

314 Fig. 3c), with butterflies being on average $15 \%$ more likely to display inspection

315 behaviours than Apis mellifera (Fig. 3c). However, ant exclusion did not affect

316 this behaviour in either pollinator group (Table 1, Fig. 3c). Avoidance differed

317 significantly between pollinator taxa, and the two taxa differed in their

318 responses to ant guards (significant ant exclusion $\times$ pollinator taxon

319 interaction; Table 1). Ant exclusion increased avoidance behaviour in

320 butterflies, but decreased it for Apis mellifera (Fig. 3d), resulting in butterflies

321 being deterred from landing on flowers following inspection three times more

322 frequently than Apis mellifera (butterflies: 27\%, Apis mellifera: 8.5\%; Fig. 3d,

323 Table 1).

When visit duration was split between inspection and contact

325 behaviours, the effect of ant exclusion on visit duration differed between

326 pollinator taxa, and behaviours (Fig. 3e, Table 1). Ant exclusion significantly

327 increased the duration of Apis mellifera contact visits $(Z=2.96, P=0.05)$,

328 increasing the time bees spent inside flowers, but did not affect the time

329 butterflies spent inside flowers (contact behaviours: $Z=-2.34, P=0.25$ ), or the

330 duration of inspection behaviours by either pollinator (Apis mellifera: $Z=-$

o.48, $P=0.99$; butterflies: $Z=-1.73, P=0.65)$. Both pollinator groups spent 
332 longer periods displaying contact behaviours than inspection behaviours,

333 regardless of the ant exclusion treatment (Table 1, Fig. 3e).

Plant mating system and pollen transfer dynamics

336 Pollen load per stigma was significantly higher in ant-excluded plants (Fig. 4a,

337 Table 1), with focal stigmas on ant-excluded plants receiving on average 155

338 more pollen grains than stigmas on control flowers (control: $85 \pm 12$; ant

339 exclusion: $240 \pm 32$ (mean \pm se); LRT $=9.19, P=0.002$; Table 2, Fig. 4a). The

340 proportion of pollen grains from each mating system category differed

341 significantly within and between plant treatments (Fig. 4b, Table 1). In

342 particular, ant exclusion halved outcrossing rates, reduced geitonogamy 33-

343 fold, and tripled selfing rates (Table 1, Fig. 4b).

Ant exclusion increased the number of selfing and allogamous pollen

345 grains from non-focal plants received by stigmas, but reduced the number of

346 geitonogamous pollen grains (Table 1, Fig. 4c). But overall, ant exclusion had

347 no effect on the number of pollen grains received and donated by flowers

348 between reciprocal pair plants (OUT_PAIR_REC: $\operatorname{control} v$ s. exclusion: Z =

$0.31, \mathrm{P}=1.00$; Fig. 4c). 
$351 \quad$ Plant fitness

352 Ant exclusion increased male fitness, assessed as the number of pollen grains

353 donated per flower, from $27.2 \pm 6.54$ pollen grains in control plants to $163 \pm$

35423.9 in ant-excluded plants (mean \pm se) (Fig 5a). Ant exclusion, mating system,

355 and their interaction all had significant effects on the number of pollen grains

356 donated per flower to different destinations (Table 1). Most of the pollen

357 donated per flower was received on the same flower's stigma as selfing pollen,

358 regardless of the exclusion treatment (Fig. 5b). Furthermore, ant patrolling

359 had no significant effect on the number of pollen grains donated to the

360 reciprocal pair plant.

362 Discussion

363 This study provides a comprehensive picture of the interaction between

364 myrmecophily and pollination by showing the ecological and behavioural

365 effects of ant patrolling on pollinators and their cascading effects on plant

366 mating system and fitness. Despite previous experimental evidence in this

367 system suggesting direct ant-pollinator conflicts (Villamil et al. 2018), and

368 contrary to our expectations, excluding ants from plants did not affect

369 pollinator community composition (Fig. 2), visitation frequency, pollinator

370 avoidance or inspection behaviours (Fig. 3). However, ant exclusion increased

371 pollinator visit duration (Fig 3), pollen load, male fitness, and selfing rates (Fig. 
372 4). To our knowledge, this is the first evidence that ant patrolling can affect

373 the host plant mating system and male plant fitness.

375 How do ants affect the plant mating system and fitness?

376 Ant exclusion doubled the time Apis mellifera spent inside flowers and

377 increased pollen load on stigmas by $150 \%$, but did not affect visitation

378 frequency. These findings are consistent with the pollinator relocation

379 hypothesis, which suggests ants can mildly deter pollinators leading to equally

380 frequent but shorter visits that enhance pollen transfer. Furthermore, ant

381 exclusion promoted a switch in the mating system from outcrossing to selfing

382 (Fig. 4b). The increase in the time Apis mellifera spent inside flowers may

383 underlie the increased selfing rates observed in ant-excluded plants: by

384 foraging longer on pollen and nectar bees are likely to transfer more pollen

385 from the anthers to the stigmas within a flower. Longer contact visits by Apis

386 mellifera in the absence of ants may also be responsible for the increased male

387 fitness, if longer visits allow Apis mellifera to collect and transport more pollen

388 grains. Hence, ants cause behavioural changes in pollinator visitation

389 dynamics that have cascading effects on the host plant mating system, and

390 ultimately influence male and female fitness. 


\section{Effects of ant patrolling on anti-predatory responses and efficiency}

Anti-predatory responses in pollinators vary depending on the pollinator and predator taxa involved (Romero et al. 2011), but few studies have documented how different floral visitors respond to ant patrolling (Ness 2006; Ohm \& Miller 2014; Carper et al. 2016) and how different ant partners affect pollinators (Ness 2006; Miller 2007; Ohm \& Miller 2014; Villamil et al. 2018). Several hypotheses have been made regarding how ants may differentially affect each pollinator depending on body size and lifestyle (social or solitary) (Clark \& Dukas 1994; Abbott \& Dukas 2009) (Romero et al. 2011). Overall, predation risk by ant patrolling in $T$. velutina was not strong enough to affect pollinator composition or increase the natural avoidance and inspection rates of pollinators. Our behavioural results are consistent with the pattern revealed in a meta-analysis by Romero et al. (2011) showing that pollinator lifestyle (social $v s$. solitary) is not a good predictor of anti-predatory sensitivity. In our study, ant patrolling reduced visit duration in Apis mellifera, but not in butterflies (Fig. 3b, Table 1). Our results show avoidance behaviours differ between pollinator taxa, a pattern consistent with previous findings suggesting different pollinators differ in their anti-predatory response behaviours (Romero et al. 2011).

The net effect of defensive mutualists on the host plant pollination and fitness can vary depending on whether predators deter efficient pollinators or inefficient visitors (Romero \& Koricheva 2011). For example, guarding ants decreased plant fitness when they attacked efficient pollinators in Ficus 
pertusa (Moraceae: Bronstein 1991) and Opuntia imbricata (Cactaceae:Ohm \&

416 Miller 2014), but had positive effects in Banistriopsis malifolia

417 (Malpighiaceae:Alves-Silva et al. 2013) where wasps protected flowers from

418 predation without deterring efficient pollinators. In T. velutina butterflies were

419 more abundant than bees, but changes in the behavioural patterns of bees, and

420 not of butterflies, (Fig. 3) seem to be driving changes in plant mating systems

421 (Fig. 4) and fitness (Fig. 5).

423 Effects of ant patrolling on plant mating system and pollen transfer

424 Although the deleterious effects of selfing and geitonogamy have been well

425 described for many species (Waser \& Price 1991; de Jong et al. 1992; Lloyd

426 1992), the decomposition of pollen on stigmas into donor components

427 (intraflower or selfing, intraplant or geitonogamy, interplant or outcrossing)

428 has rarely been performed, and its importance remains underappreciated (de

429 Jong et al. 1993; Wu et al. 2018). We assessed the effects of ant patrolling on

430 plant mating system decomposing pollen transfer based on its origin and fate

431 finding that in this self-compatible species, ant exclusion shifted the plant

432 mating system from predominantly outcrossing to predominantly selfing,

433 reducing geitonogamy (Fig. 4b). In bisexual flowers self-pollination can be

434 mediated by pollinators (Wu et al. 2018) and we suggest that this is the case for

435 T. velutina where ant patrolling reduced selfing rates by affecting pollinator

436 visitation behaviour, reducing the time bees spent inside flowers. 
439 data on pollen transfer (showing counts of pollen grains from different donors)

440 it becomes evident that the increase in pollen load in the absence of ants is

441 driven by selfing and allogamous pollen from other undyed, surrounding, $T$.

442 velutina plants. The number of selfing pollen grains on ant-excluded stigmas

443 was much higher, likely driving the change in the mating system from

444 outcrossing to selfing. Yet, ant exclusion also increased the number of

445 allogamous pollen grains received by the stigmas. The significant increase in

446 the number of geitonogamous pollen grains received by ant-patrolled stigmas

447 (Fig. 4C) is consistent with the pollinator relocation hypothesis, which

448 proposes that ant patrolling mildly deters pollinators, causing them to move to

449 a nearby flower and hence increasing the rate of geitonogamy in the plant

450 (Altshuler 1999; Romero \& Koricheva 2011). Our results suggest that ants

451 contribute to maintaining outcrossing in the self-compatible T. velutina.

453 Effects of ant patrolling on plant fitness

454 A complete understanding of the effects mutualists and antagonists have on

455 plant fitness requires the assessment of both female and male fitness

456 components, because the magnitude and direction of the effects may differ

457 between plant sexual functions (Schaeffer et al. 2013; Carper et al. 2016). For

458 instance, male fitness is more constrained by the number of mates reached

459 than female fitness; and pollinator behaviour affects pollen transfer, with 
460 longer visits increasing pollen export and pollen deposition on stigmas (Carper

461 et al. 2016). Consequently, we expect male fitness to be more susceptible to

462 changes in pollinator behaviour (Krupnick \& Weis 1999; Schaeffer et al. 2013;

463 Carper et al. 2016). To date, very little has been done to assess the effect of ant

464 patrolling on female fitness, and we are not aware of any study assessing the

465 effects of ants on male plant fitness. Our experimental design allowed us to

466 quantify the consequences of ant patrolling on male reproductive fitness

467 (pollen grains donated per flower) and infer potential effects on female fitness

468 (progeny quality). Ant exclusion resulted in a six-fold increase in the number

469 of pollen grains donated per flower (Fig. 5a), suggesting that guarding ants

470 may hinder male fitness.

Ant exclusion changed the pollen destination, given that most pollen

472 was donated towards selfing, which contrasts with flowers from ant-patrolled

473 flowers which donated a quarter as much pollen to themselves (Fig. 5b).

474 Hence, ant patrolling in T. velutina's may increase female fitness by promoting

475 outbred seeds and so increasing the offspring quality. Our findings contrast

476 with previous studies showing negative effects of ant patrolling on female

477 plant fitness. In Opuntia imbricata ant patrolling decreased seed count by $30 \%$

478 and seed mass by $16 \%$ (Ohm \& Miller 2014); and in Heteropterys physophora

479 ants consumed floral buds, deterred pollinators, reduced pollen transfer and

480 fruit set in buds that escaped ant predation (Malé et al. 2012). Furthermore,

481 our findings exemplify how non-pollinators insects interacting with plants and

482 their pollinators may have contrasting effects on female and male fitness 
483 components, highlighting the importance of considering both sexual

484 functions.

This study provides a comprehensive picture of the interaction between

486 myrmecophily and pollination by showing the ecological and behavioural

487 effects of ant patrolling on pollinators and its cascading effects on plant

488 mating systems that lead to fitness consequences. Contrary to our initial

489 prediction, ant patrolling benefited plant fitness by reducing pollinator visit

490 duration, which promoted pollinator relocation, and led to a reduction in

491 selfing and an increase in outcrossing rates. Although ant patrolling reduced

492 pollen load and male fitness, far from having an ecological cost on the host,

493 ant patrolling seems to be another mechanism - along with herkogamy and

494 pollinator attracting features (Sosenski et al. 2016)- to promote outcrossing in

495 this self-compatible species with hermaphroditic flowers. This study

496 contributes towards our understanding on how non-pollinators can shape

497 plant mating systems. We provide the first evidence of the role of patrolling

498 ants on determining plant mating systems and male plant fitness by taking a

499 multispecies approach on plant-animal interactions.

\section{Acknowledgements}

We thank Aura Larsson and Alberto Herrera for their help during fieldwork,

503 Rubén Pérez-Ishiwara for logistical assistance, Jarrod Hadfield for valuable 
504 inputs towards the statistical analyses, and Ally Phillimore for comments

which greatly enhanced previous versions of the manuscript.

pollinators: their conservation BB/1000305/1 granted to GNS.

\section{References}

1.

512 Abbott, K.R. \& Dukas, R. (2009). Honeybees consider flower danger in their waggle dance. Animal Behaviour, 78, 633-635.

515 Altshuler, D.L. (1999). Novel interactions of non-pollinating ants with pollinators and fruit consumers in a tropical forest. Oecologia, 119, 6oo606.

3.

533 Bates, D., Maechler, M., Bolker, B., Walker, S., Christensen, R.H.B., Singmann, nectar consumption and herbivore predation in a tending ant system.

4 . Entomological Science, 16, 162-169.

Arbo, M.M. (2005). Estudios sistemáticos en Turnera (Turneraceae). III. Series Anomalae y Turnera. Bonplandia, 14, 115-318.

5.

Assunção, M.A., Torezan-Silingardi, H.M. \& Del-Claro, K. (2014). Do ant visitors to extrafloral nectaries of plants repel pollinators and cause an indirect cost of mutualism? Flora-Morphology, Distribution, Functional Ecology of Plants, 209, 244-249.

7.

Beattie, A.J. (1985). The evolutionary ecology of ant-plant mutualisms.

8. Cambridge University Press.

Bentley, B. (1977). Extrafloral nectaries and protection by pugnacious bodyguards. Annual Review of Ecology and Systematics, 8, 407-427. 
9.

Bronstein, J.L. (1991). The nonpollinating wasp fauna of Ficus pertusa: exploitation of a mutualism? Oikos, 175-186. 10.

Carper, A.L., Adler, L.S. \& Irwin, R.E. (2016). Effects of florivory on plant-pollinator interactions: Implications for male and female components of plant reproduction. American Journal of botany, 103, 1061-1070.

11.

Clark, C.W. \& Dukas, R. (1994). Balancing foraging and antipredator demands: an advantage of sociality. The American Naturalist, 144, 542-548. 12.

Clinchy, M., Sheriff, M.J. \& Zanette, L.Y. (2013). Predator-induced stress and the ecology of fear. Functional Ecology, 27, 56-65.

13.

Cuautle, M. \& Rico-Gray, V. (2003). The effect of wasps and ants on the reproductive success of the extrafloral nectaried plant Turnera ulmifolia (Turneraceae). Functional Ecology, 17, 417-423.

14 .

Cuautle, M., Rico-Gray, V. \& Díaz-Castelazo, C. (2005). Effects of ant behaviour and presence of extrafloral nectaries on seed dispersal of the Neotropical myrmecochore Turnera ulmifolia L.(Turneraceae). Biological Journal of the Linnean Society, 86, 67-77.

15.

de Jong, T.J., Waser, N.M. \& Klinkhamer, P.G. (1993). Geitonogamy: the neglected side of selfing. Trends in Ecology E Evolution, 8, 321-325. 16.

de Jong, T.J., Waser, N.M., Price, M.V. \& Ring, R.M. (1992). Plant size, geitonogamy and seed set in Ipomopsis aggregata. Oecologia, 89, 310315.

17.

Dukas, R. (2001). Effects of perceived danger on flower choice by bees. Ecology Letters, 4, 327-333.

18.

Dukas, R. \& Morse, D.H. (2003). Crab spiders affect flower visitation by bees. Oikos, 101, 157-163.

19.

Dutton, E.M. \& Frederickson, M.E. (2012). Why ant pollination is rare: new evidence and implications of the antibiotic hypothesis. Arthropod-Plant Interactions, 6, 561-569.

20.

Frederickson, M.E. (2009). Conflict over Reproduction in an Ant-Plant Symbiosis: Why Allomerus octoarticulatus Ants Sterilize Cordia nodosa Trees. The American Naturalist, 173, 675-681.

21. 
Gaume, L., Zacharias, M. \& Borges, R.M. (2005). Ant-plant conflicts and a novel case of castration parasitism in a myrmecophyte. Evolutionary Ecology Research, 7, 435-452.

22.

Goncalves-Souza, T., Omena, P.M., Souza, J.C. \& Romero, G.Q. (2008). Trait-mediated effects on flowers: artificial spiders deceive pollinators and decrease plant fitness. Ecology, 89, 2407-2413.

23.

Hothorn, T., Bretz, F., Westfall, P. \& Heiberger, R. (2008). Multcomp: simultaneous inference for general linear hypotheses. R Package Version 1.0-3.

24 .

Jones, I.M. \& Koptur, S. (2015). Dynamic extrafloral nectar production: the timing of leaf damage affects the defensive response in Senna mexicana var. chapmanii (Fabaceae). American journal of botany, 102, 58-66.

25.

Kearns, C.A. \& Inouye, D.W. (1993). Techniques for pollination biologists. University Press of Colorado, Niwot, Colorado. 26.

Koptur, S., Jones, I.M. \& Peña, J.E. (2015). The influence of host plant extrafloral nectaries on multitrophic interactions: an experimental investigation. PloS one, 10, eo138157.

27.

Krupnick, G.A. \& Weis, A.E. (1999). The effect of floral herbivory on male and female reproductive success in Isomeris arborea. Ecology, 8o, 135-149. 28.

Lloyd, D.G. (1992). Self-and cross-fertilization in plants. II. The selection of self-fertilization. International Journal of Plant Sciences, 153, 370-380. 29.

Malé, P.-J.G., Leroy, C., Dejean, A., Quilichini, A. \& Orivel, J. (2012). An ant symbiont directly and indirectly limits its host plant's reproductive success. Evolutionary ecology, 26, 55-63. 30.

Malé, P.-J.G., Leroy, C., Lusignan, L., Petitclerc, F., Quilichini, A. \& Orivel, J. (2015). The reproductive biology of the myrmecophyte, Hirtella physophora, and the limitation of negative interactions between 31. pollinators and ants. Arthropod-Plant Interactions, 9, 23-31.

Martin, H. \& Doyle, M. (2003). P ROTECTIVE A NT-PLANT I NTERACTIONS AS M ODEL S YSTEMS IN E COLOGICAL AND E VOLUTIONARY R ESEARCH. Annual Review of Ecology, Evolution, and Systematics, 34. 32.

Miller, T.E.X. (2007). Does having multiple partners weaken the benefits of facultative mutualism? A test with cacti and cactus-tending ants. Oikos, $116,500-512$. 
33.

Ness, J.H. (2006). A mutualism's indirect costs: the most aggressive plant bodyguards also deter pollinators. Oikos, 113, 506-514.

34

Ochoa Sánchez, M.A. (2016). El valor funcional de la integración floral en Turnera velutina. In: Departamento de Ecología Evolutiva, Instituto de Ecología. Universidad Nacional Autónoma de México (UNAM) México, p. 50.

35 .

Ohm, J.R. \& Miller, T.E. (2014). Balancing anti-herbivore benefits and anti-pollinator costs of defensive mutualists. Ecology, 95, 2924-2935.

36.

Preisser, E.L., Bolnick, D.I. \& Benard, M.F. (2005). Scared to death? The effects of intimidation and consumption in predator-prey interactions. Ecology, 86, 501-509.

37.

Romero, G.Q., Antiqueira, P.A. \& Koricheva, J. (2011). A meta-analysis of predation risk effects on pollinator behaviour. PloS one, 6, e2o689. 38.

Romero, G.Q. \& Koricheva, J. (2011). Contrasting cascade effects of carnivores on plant fitness: a meta-analysis. Journal of Animal Ecology, 8o, 696704 .

39.

Schaeffer, R.N., Manson, J.S. \& Irwin, R.E. (2013). Effects of abiotic factors and species interactions on estimates of male plant function: a meta-analysis. Ecology letters, 16, 399-408.

40.

Sheriff, M.J. \& Thaler, J.S. (2014). Ecophysiological effects of predation risk; an integration across disciplines. Oecologia, 176, 607-611.

41.

Sosenski, P., Ramos, S., Domínguez, C.A., Boege, K. \& Fornoni, J. (2016). Pollination biology of the hexaploid self-compatible species Turnera velutina (Passifloraceae). Plant Biology, 19, 101-107.

42.

Stanton, M.L. \& Palmer, T.M. (2011). The high cost of mutualism: effects of four species of East African ant symbionts on their myrmecophyte host tree. Ecology, 92, 1073-1082.

43.

Stanton, M.L., Palmer, T.M., Young, T.P., Evans, A. \& Turner, M.L. (1999). Sterilization and canopy modification of a swollen thorn acacia tree by a plant-ant. Nature, 401, 578-581.

44 .

Villamil, N., Boege, K. \& Stone, G. (2018). Ant-pollinator conflict results in pollinator deterrence but no nectar trade-offs. Frontiers in Plant Science, 9, 1093. 
676

677

678

679

680

681

682

683

684

685

686

687

688

689

690

691

692

693

694

695

696

697

698

699
45.

Villamil, N., Márquez-Guzmán, J. \& Boege, K. (2013). Understanding ontogenetic trajectories of indirect defence: ecological and anatomical constraints in the production of extrafloral nectaries. Annals of Botany, 46. 112, 701-709.

Waser, N.M. \& Price, M.V. (1991). Reproductive costs of self-pollination in Ipomopsis aggregata (Polemoniaceae): are ovules usurped? American Journal of Botany, 78, 1036-1043.

47.

Wu, L.Y., Chang, F.F., Liu, S.J., Scott Armbruster, W. \& Huang, S.Q. (2018). Heterostyly promotes compatible pollination in buckwheats: Comparisons of intraflower, intraplant, and interplant pollen flow in distylous and homostylous Fagopyrum. American journal of botany, 105, 108-116.

48.

Zedillo-Avelleyra, P. (2017). Variación genética en la expresión de trayectorias ontogenéticas de la defensa de Turnera velutina In: Posgrado en Ciencias Biológicas, Instituto de Ecología. Universidad Nacional Autónoma de México Ciudad de México, p. 72. 
701 Figure 1. Experimental design and methods. (a) Diagram of the experimental setup

702 showing a plant pair with or without ant patrolling. Within each experimental plant,

703 the focal flower is represented by a uniquely coloured circle, and satellite flowers are

704 the five circles coloured differently. The surrounding bushes with yellow circles represent undyed (naturally yellow) flowers from neighbouring plants bagged to secure allogamous pollen. (b) Photograph of dyed pollen on the anthers (dp) and dyed pollen grain on the flower stigmas (ps). (c) Photograph of stigma squash slides with dyed pollen grains.

709 Figure 2. Composition of floral visitors visiting Turnera velutina plants with and 710 without ant patrolling.

711 Figure 3. Effects of ant patrolling on pollinator visitation by Apis mellifera and native

712 butterflies on Turnera velutina flowers on control plants with ant patrolling (black),

713 and ant excluded plants (white) showing mean \pm se for: (a) pollinator visitation

714 frequency, (b) visit duration, and (c-e) pollinator behaviours affecting (c) the time

715 spent displaying alert (circles) or contact/presence behaviours (triangles), (d) the

716 display of alert behaviours, (e) the likelihood of deterrence.

717 Figure 4. Effects of ant patrolling on the (a) pollen load, (b) mating system rates and

718 (c) pollen flow (origin and destination) in Turnera velutina showing mean \pm se for

719 control (black) and ant-excluded (white) plants.

720 Figure 5. Effects of ant patrolling on male fitness, showing (a) average number pollen

721 grains fathered per flower, and (b) the destination of the pollen grains donated per

722 flower (mean \pm se) for control (black) and ant excluded (white) plants. 
bioRxiv preprint doi: https://doi.org/10.1101/2020.02.11.943431; this version posted February 12, 2020. The copyright holder for this preprint (which was not certified by peer review) is the author/funder, who has granted bioRxiv a license to display the preprint in perpetuity. It is made available under aCC-BY-NC-ND 4.0 International license.

724 Table 1.

725 Model statistics testing the costs of ant patrolling on Turnera velutina's pollination

726 biology, including ecological, behavioural, mating system, and fitness consequences.

727 
b)

731

732

c)

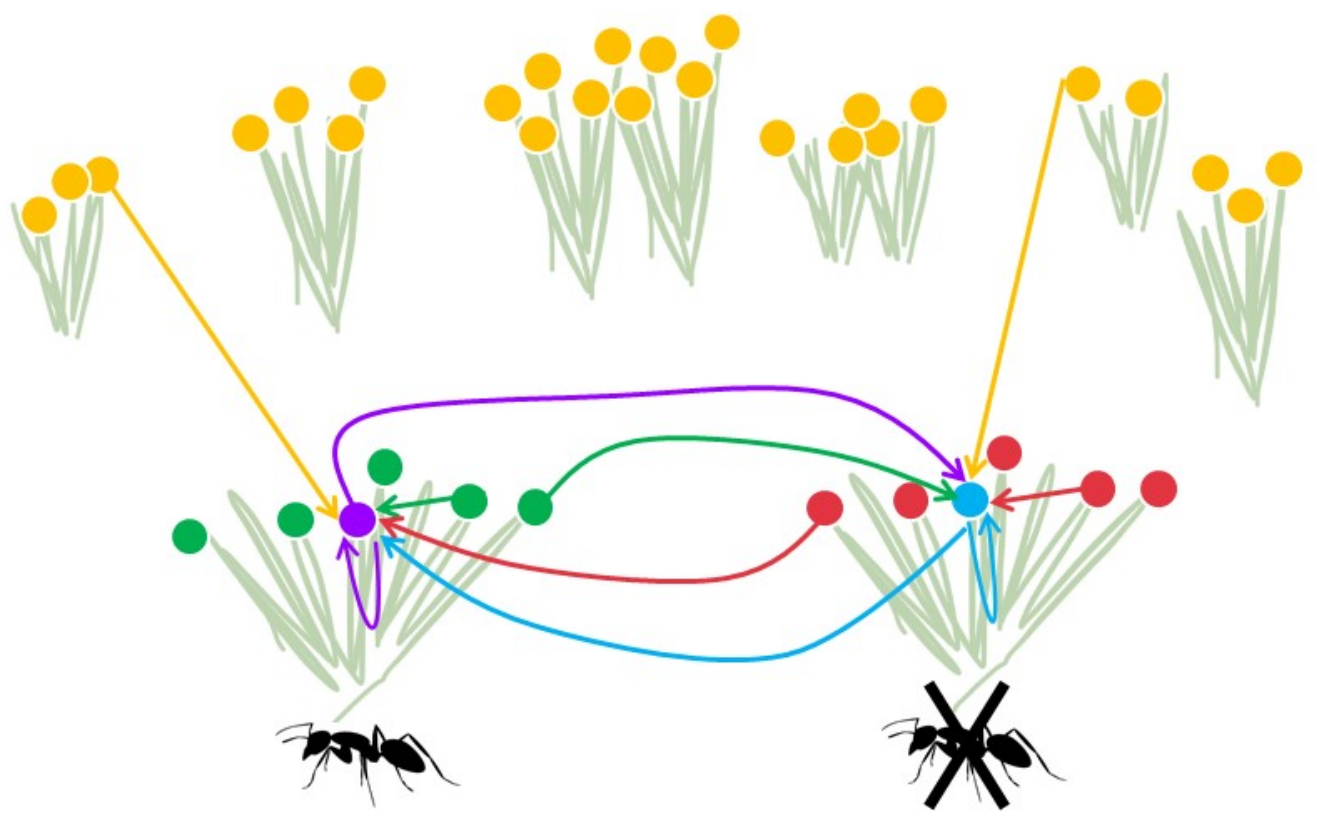

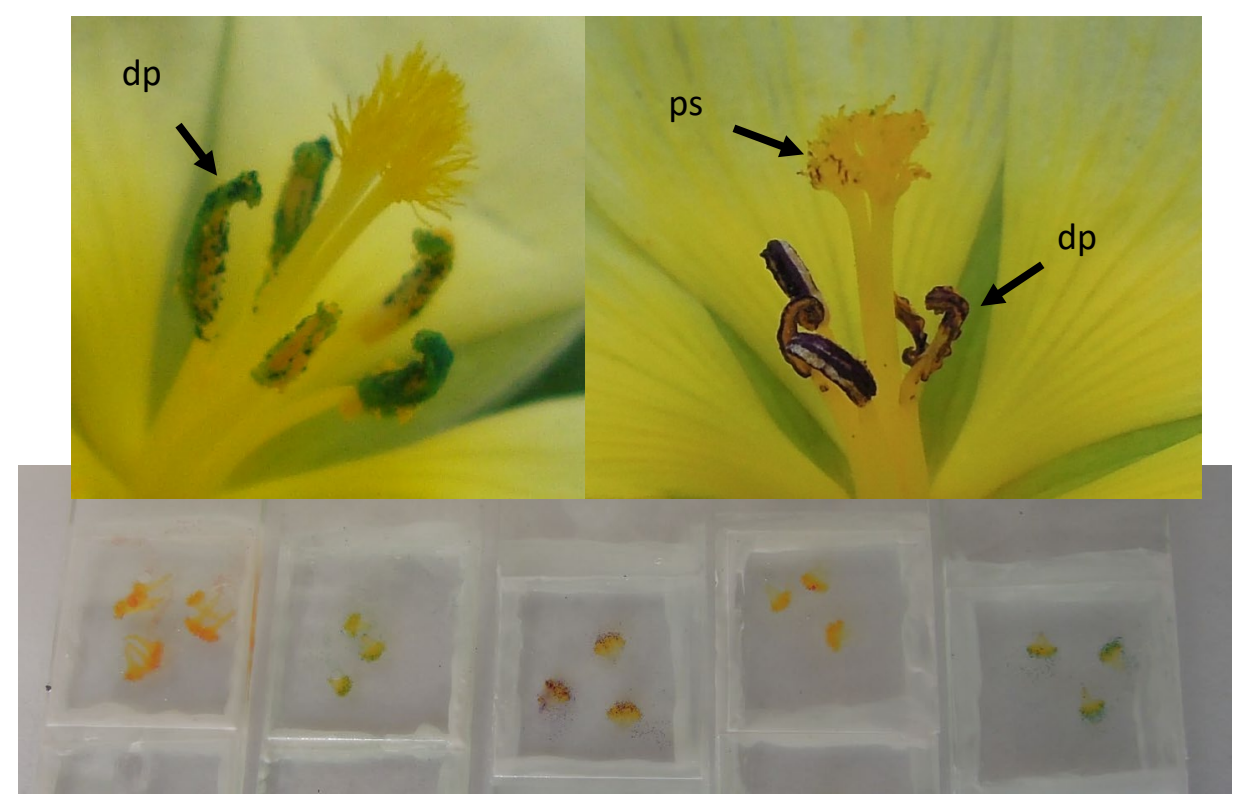

Figure 1. Experimental design and methods. (a) Diagram of the experimental setup showing a plant pair with or without ant patrolling. Within each experimental plant, the focal flower is represented by a uniquely coloured circle, and satellite flowers are the five circles coloured differently. The surrounding bushes with yellow circles represent undyed (naturally yellow) flowers from neighbouring plants bagged to secure allogamous pollen. (b) Photograph of dyed pollen on the anthers (dp) and 
bioRxiv preprint doi: https://doi.org/10.1101/2020.02.11.943431; this version posted February 12, 2020. The copyright holder for this preprint (which was not certified by peer review) is the author/funder, who has granted bioRxiv a license to display the preprint in perpetuity. It is made available under aCC-BY-NC-ND 4.0 International license.

745 dyed pollen grain on the flower stigmas (ps). (c) Photograph of stigma squash slides

746 with dyed pollen grains.

747 
bioRxiv preprint doi: https://doi org/10.1101/2020.02 11.943431· this version posted February 12, 2020. The copyright holder for this preprint (which was not certified by peer review) is the author/funder, who has granted bioRxiv a license to display the preprint in perpetuity. It is made available under aCC-BY-NC-ND 4.0 International license.

748

749

750

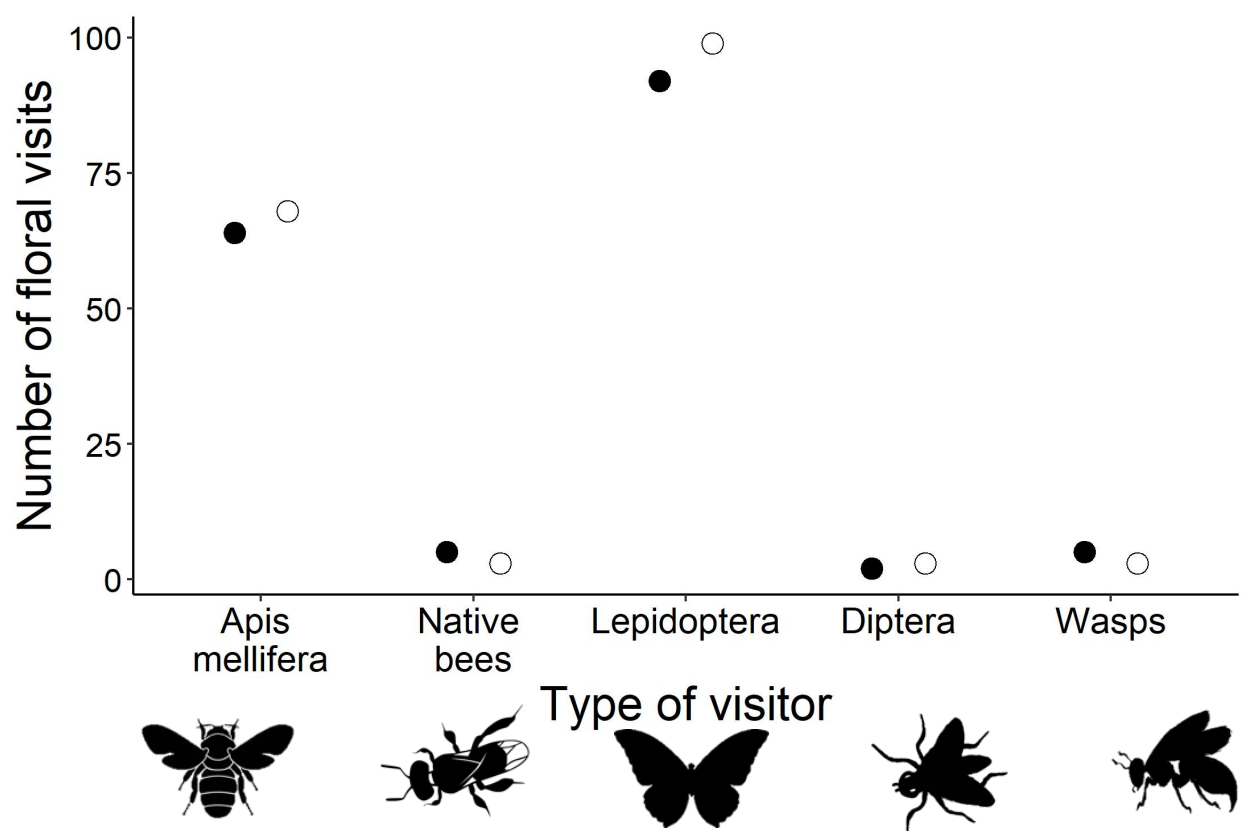

751 Figure 2. Composition of floral visitors in Turnera velutina plants with and without 752 ant patrolling. 
a)

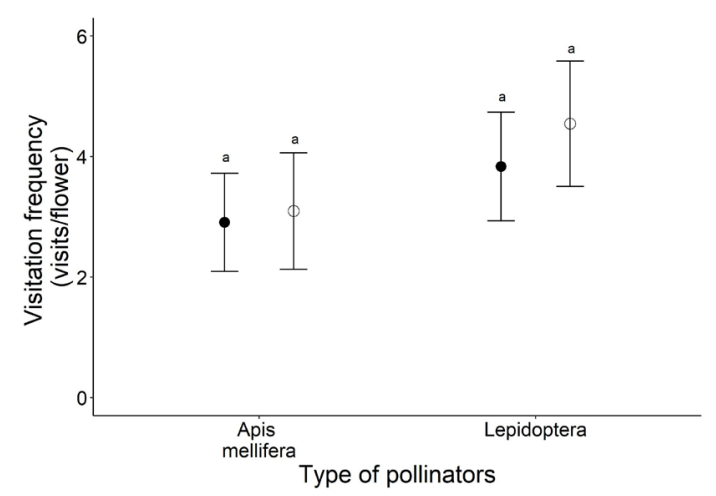

d)

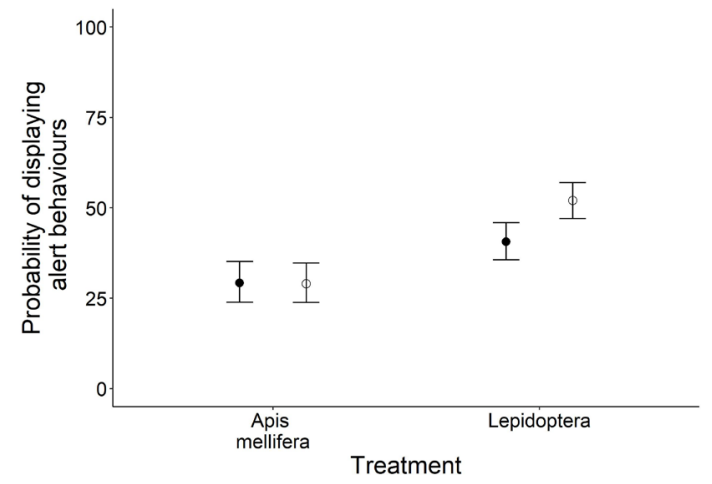

b)

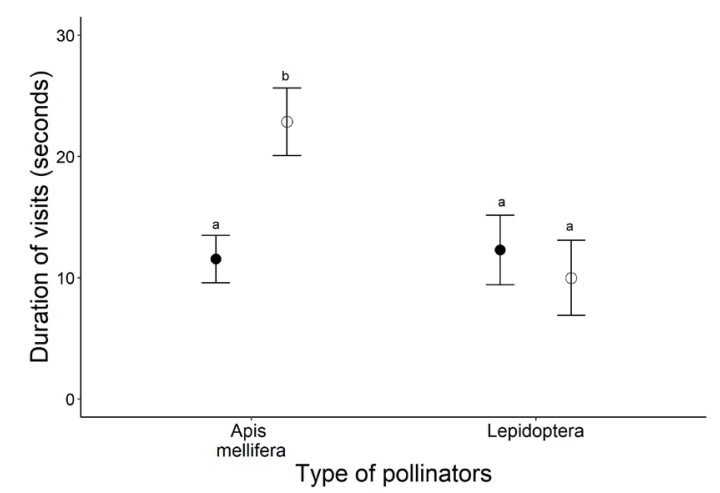

e)

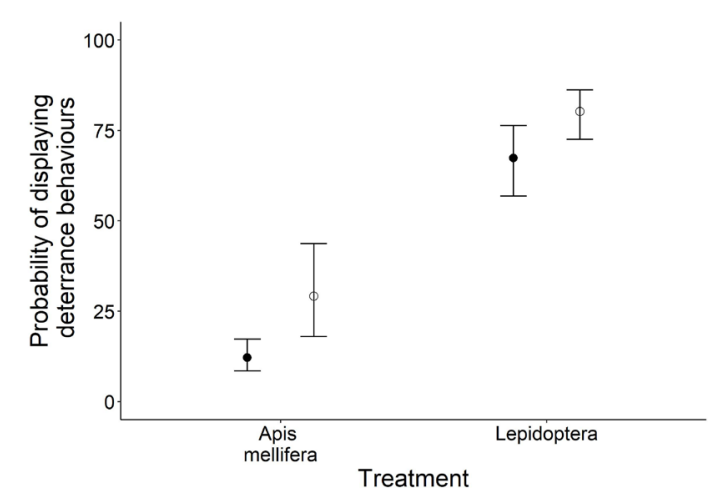

c)

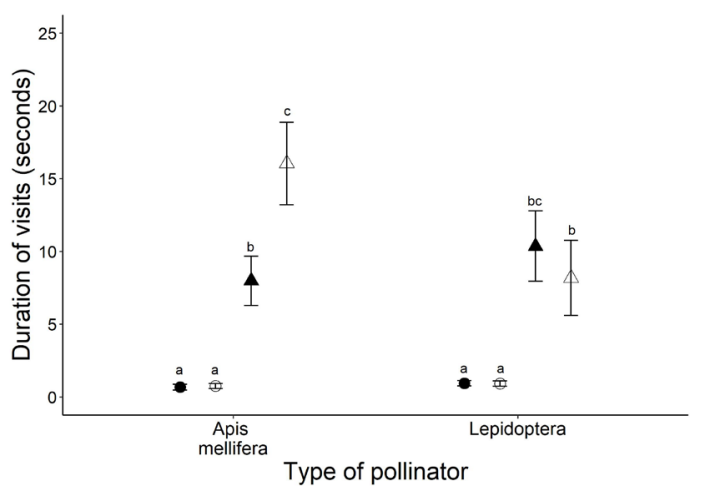

Figure 3. Effects of ant patrolling on pollinator visitation by Apis mellifera and native butterflies on Turnera velutina flowers on control plants with ant patrolling (black), and ant excluded plants (white). (a) Pollinator visitation frequency, (b) visit duration, and (c-e) pollinator behaviours affecting (c) the time spent displaying alert (circles) or contact/presence behaviours (triangles), (d) the display of alert behaviours, (e) the likelihood of deterrence.

\section{Alert \\ $\triangle$ Presence \\ Treatment \\ - Control \\ - Exclusion}

haviour 
1

a)

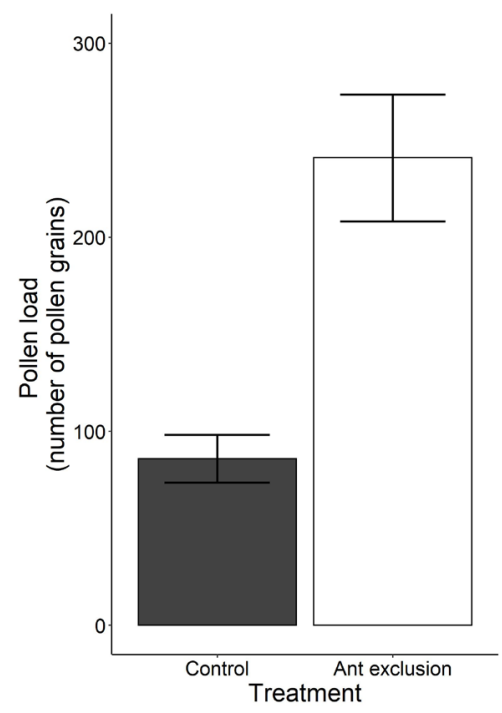

b)

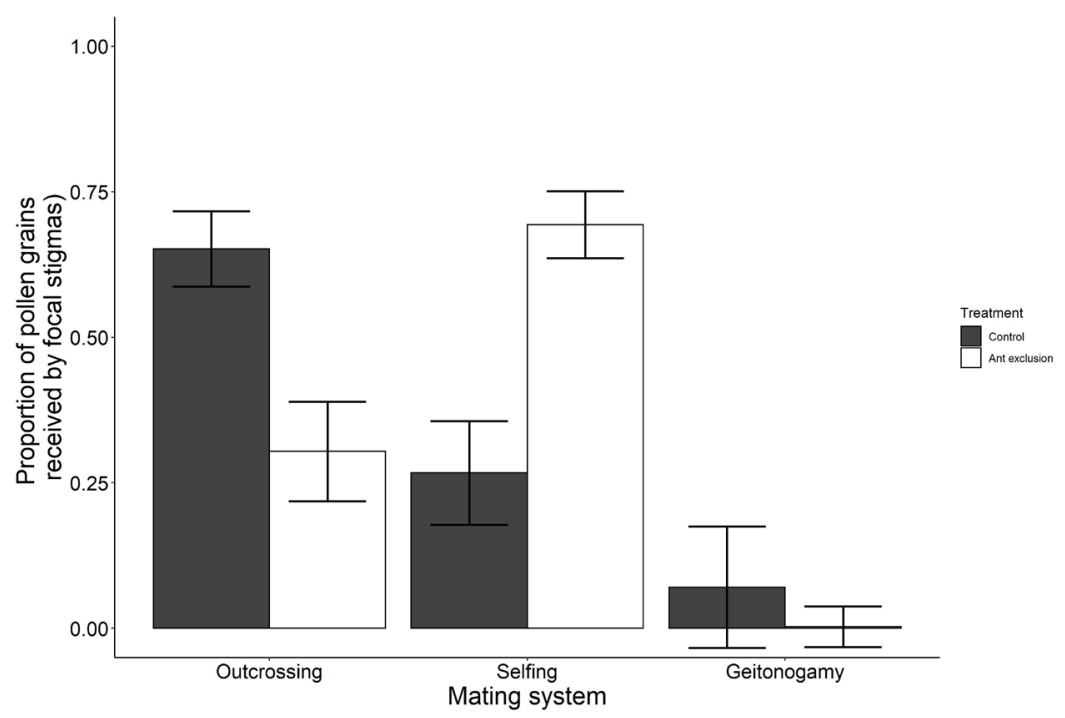

4 c)

MSPO: Pollen transfer dynamics

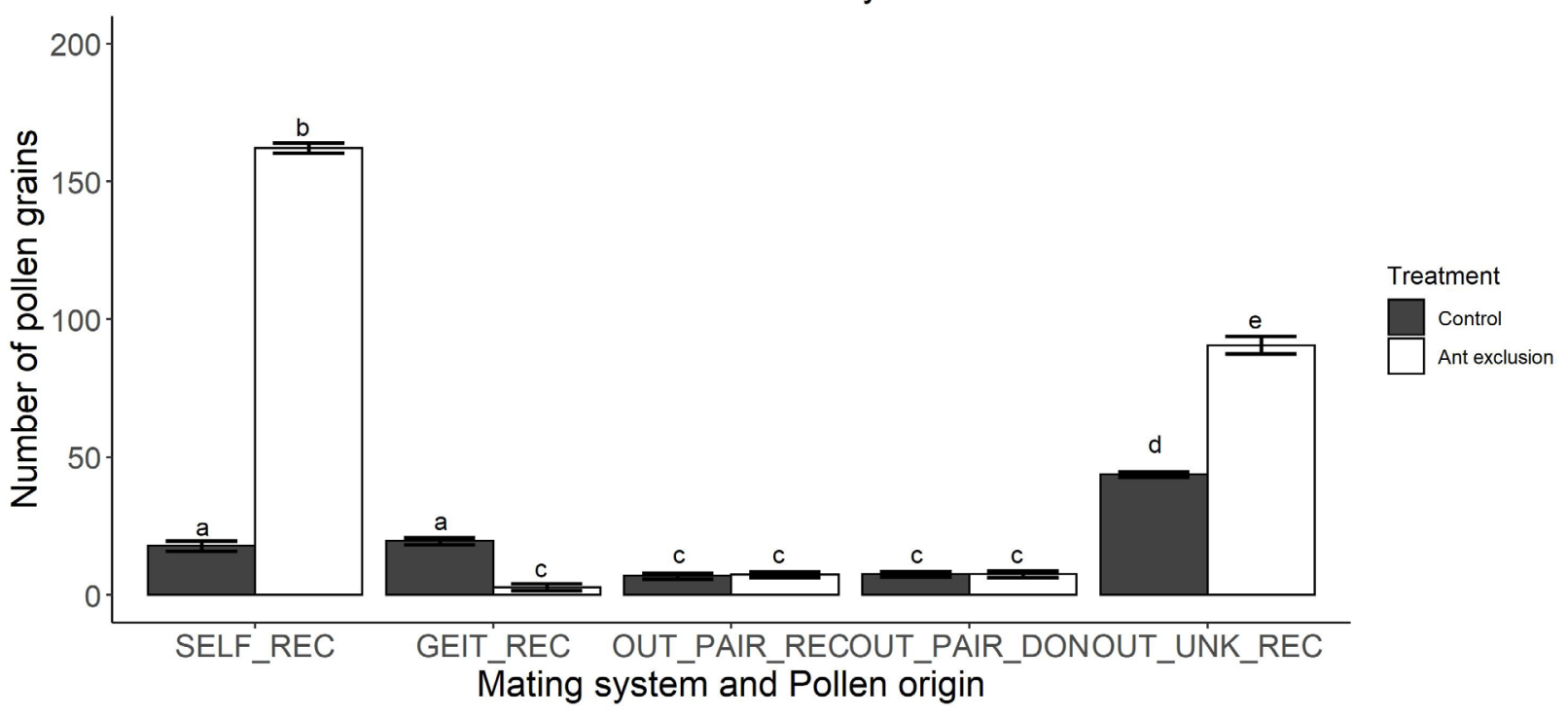

6 Figure 4. Effects of ant patrolling on the (a) pollen load, (b) mating system rates and (c) pollen

7 flow (origin and destination) in Turnera velutina showing mean \pm se for control (black) and ant-

8 excluded (white) plants. 

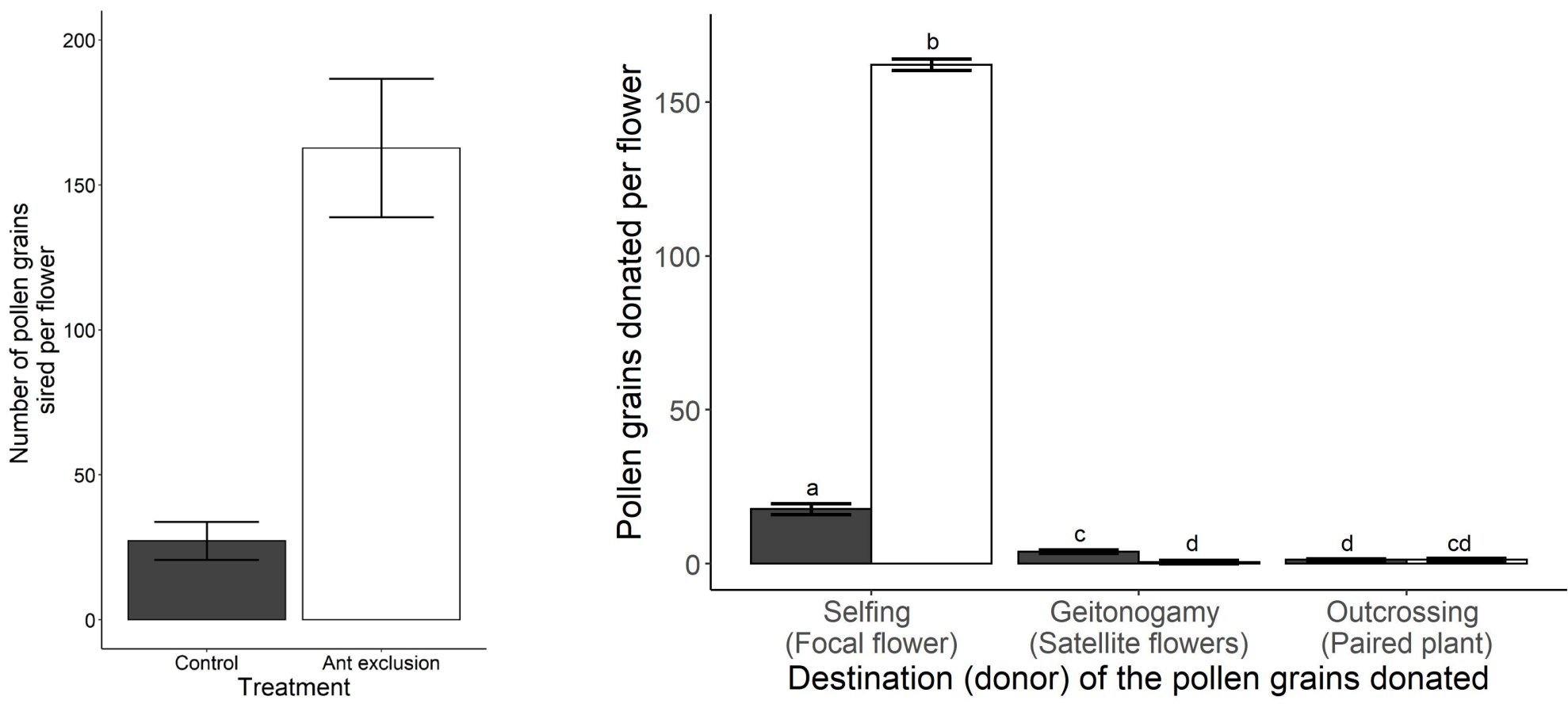

Figure 5. Effects of ant patrolling on male fitness, showing (a) average number pollen grains fathered per flower, and (b) the destination of the pollen grains donated per flower (mean \pm se) for control (black) and ant excluded (white) plants. 
Table 1. Model statistics testing the costs of ant patrolling on Turnera velutina's pollination biology, including ecological, behavioural, mating system, and fitness consequences.

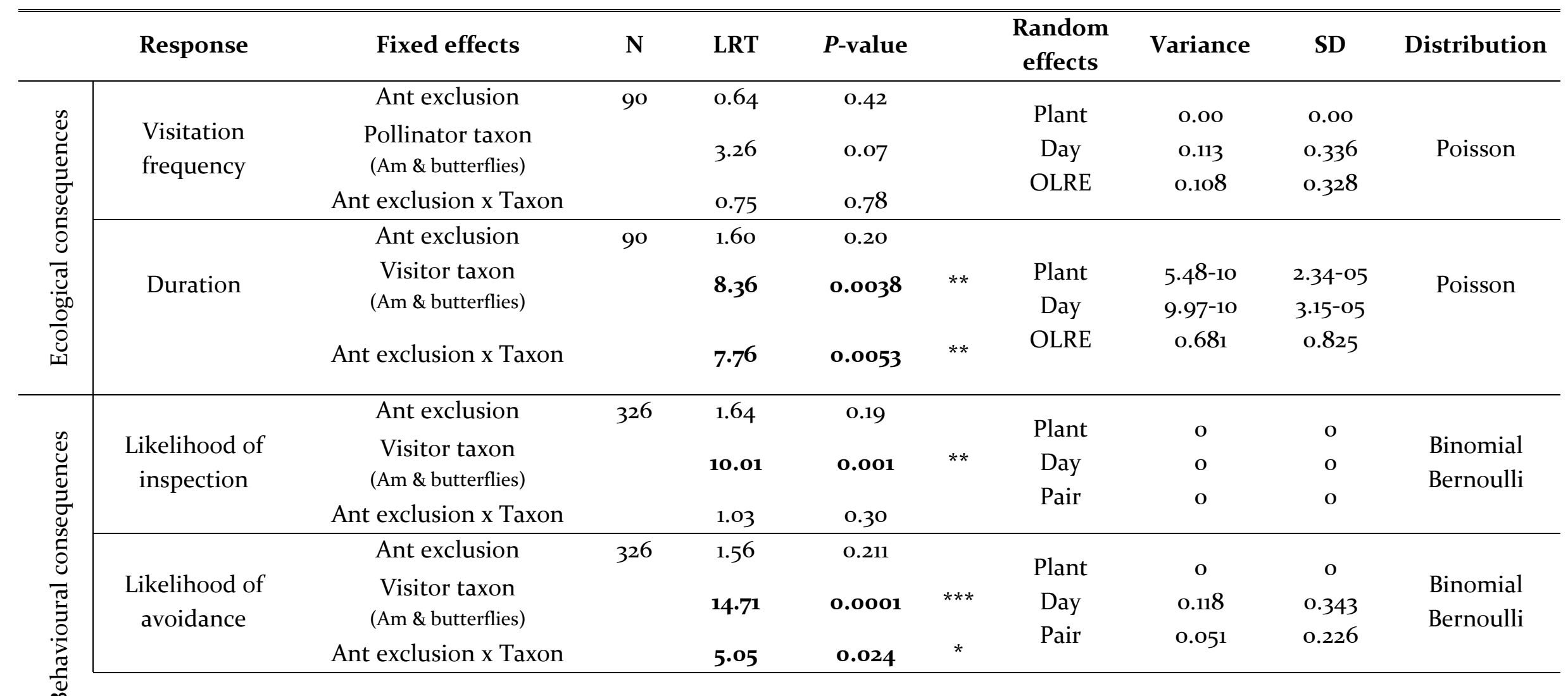




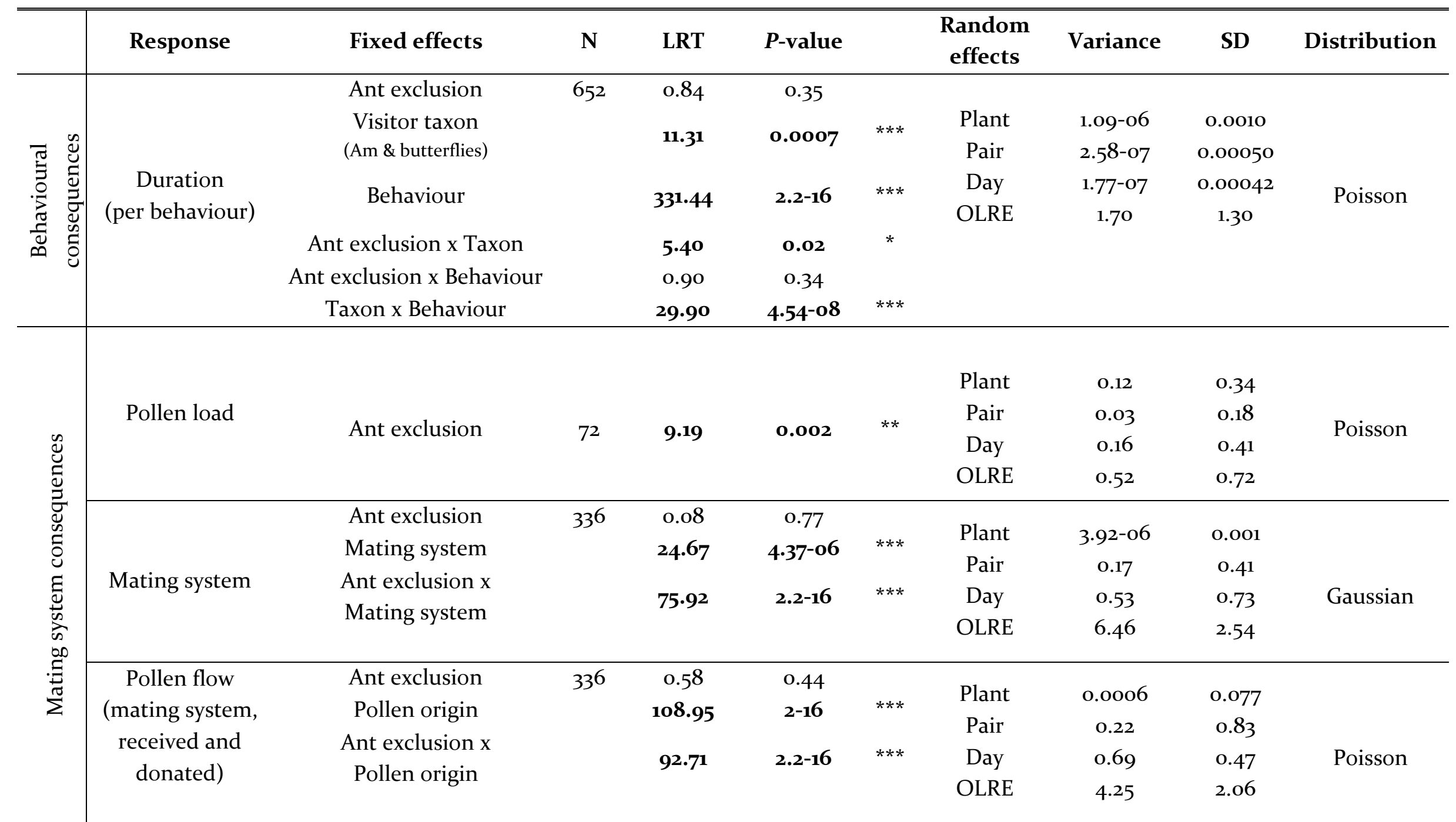




\begin{tabular}{|c|c|c|c|c|c|c|c|c|c|c|}
\hline & Response & Fixed effects & $\mathbf{N}$ & LRT & $P$-value & & $\begin{array}{c}\text { Random } \\
\text { effects }\end{array}$ & Variance & SD & Distribution \\
\hline \multirow{2}{*}{ 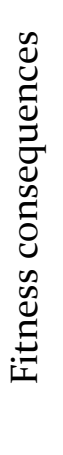 } & Male fitness & Ant exclusion & 72 & $9 \cdot 56$ & 0.001 & $* *$ & $\begin{array}{c}\text { Plant } \\
\text { Pair } \\
\text { Day } \\
\text { OLRE }\end{array}$ & $\begin{array}{l}0.12 \\
0.03 \\
0.16 \\
0.52\end{array}$ & $\begin{array}{l}0.34 \\
0.18 \\
0.41 \\
0.72\end{array}$ & Poisson \\
\hline & $\begin{array}{l}\text { Destination of } \\
\text { donated pollen }\end{array}$ & Ant exclusion & 200 & $3 \cdot 93$ & 0.04 & $*$ & $\begin{array}{c}\text { Plant } \\
\text { Pair } \\
\text { Day } \\
\text { OLRE }\end{array}$ & $\begin{array}{c}0.16 \\
0.004 \\
0.44 \\
2.99\end{array}$ & $\begin{array}{l}0.40 \\
0.06 \\
0.67 \\
1.72\end{array}$ & Poisson \\
\hline
\end{tabular}

